\title{
Utilização do Soro de Mandioca como Substrato Fermentativo para a Biosíntese de Goma Xantana: Viscosidade Aparente e Produção
}

\author{
Líllian V. Brandão \\ Departamento de Engenharia Química, UFBA \\ Maria C. A. Esperidião \\ Departamento de Físico-Química, UFBA \\ Janice I. Druzian \\ Departamento de Análises Bromatológicas, UFBA
}

\begin{abstract}
Resumo: Goma xantana é um biopolímero comercial produzido por fermentação de glicose e Xanthomonas com larga aplicação industrial. O objetivo deste trabalho foi estudar a síntese e a viscosidade da goma obtida por cepas nativas de Xanthomonas campestris utilizando soro de mandioca como substrato fermentativo alternativo. Três tipos de Xanthomonas foram utilizados. A maior produção foi de 13,83 g.L ${ }^{-1}$ obtida do meio fermentativo com $X$. campestris mangiferaeindicae a $25{ }^{\circ} \mathrm{C}, 250 \mathrm{rpm}$ por 120 horas apresentando uma viscosidade aparente de $96,14 \mathrm{cP}$ na concentração de $2,0 \%$ de solução de xantana a $25 \mathrm{~s}^{-1}, 25^{\circ} \mathrm{C}$. O uso do resíduo industrial de soro de mandioca para biossíntese da xantana é uma alternativa de baixo custo para o processo fermentativo e um destino para esse soro.
\end{abstract}

Palavras-chave: Soro de mandioca, goma xantana, biosíntese.

\section{Use of the Cassava Serum as Fermentative Substrate in Xanthan Gum Biosynthesis: Apparent Viscosity and Production}

Abstract: Xanthan gum is a commercial biopolymer produced by fermentation of glucose and Xanthomonas with many industrial applications. The objective of this work was to study the synthesis and the viscosity of xanthan obtained from native strains of Xanthomonas campestris using cassava as an alternative fermentative substrate. Three kinds of Xanthomonas were used. The highest production was 13.83 g.L $\mathrm{L}^{-1}$ obtained with X. campestris mangiferaeindicae fermented at $25{ }^{\circ} \mathrm{C}, 250 \mathrm{rpm}$ during 120 hours and presenting apparent viscosity $96.14 \mathrm{cP}$ in the concentration of $2.0 \%$ of xanthan solution at $25 \mathrm{~s}^{-1}, 25^{\circ} \mathrm{C}$. The use of the industrial residue of cassava serum for biosynthesis of xanthan is a low cost alternative for the fermentation process and a noble use for this waste.

Keywords: Cassava serum, xanthan gum, biosynthesis.

\section{Introdução}

Agoma xantanaé um biopolímero classificado como heteroexopolissacarídeo ramificado, aniônico, produzido por fermentação com bactérias Xanthomonas campestris. Essas bactérias apresentam células em forma de bastonetes, gram-negativas e ocorrem predominantemente isoladas ${ }^{[1]}$.

A xantana é um polissacarídeo de elevado interesse industrial, principalmente para a indústria de alimentos, farmacêutica e petroquímica. Nesses setores há uma contínua substituição dos polissacarídeos convencionais por produtos de origem microbiana, por inúmeras razões, como a possibilidade de modificação de suas características reológicas através do controle de parâmetros de fermentação, da independência climática, entre outras ${ }^{[2-3]}$.

$\mathrm{O}$ grande interesse comercial pelo produto deve-se as suas propriedades físico-químicas que superam as de todos os outros polissacarídeos disponíveis no mercado. Dentre estas propriedades destaca-se a elevada viscosidade em soluções aquosas em baixas concentrações $(0,05-1 \%)$, devido à estrutura ramificada e alto peso molecular, bem como estabilidade em ampla faixa de temperatura e $\mathrm{pH}$ e comportamento pseudoplástico ${ }^{[2-3]}$. O efeito tixotrópico em soluções poliméricas é de grande utilidade para setor de cosméticos, como loções e xampus, pois facilita a retirada do produto da embalagem, sem ocorrer escorrimento exagerado, e seu espalhamento durante a utilização ${ }^{[4]}$.
Os requerimentos nutricionais mínimos necessários do meio fermentativo para a biosíntese de xantana são as fontes de $\mathrm{C}$ (carbono), $\mathrm{N}$ (nitrogênio) e $\mathrm{P}$ (fósforo). A fonte de $\mathrm{C}$ comercial é a glicose, o que representa um fator crítico para a produção do polissacarídeo ${ }^{[3]}$. Embora a goma xantana ainda não seja produzida comercialmente no Brasil, a sacarose como fonte de carbono representaria um menor custo de produção. Apesar da goma xantana ter propriedades reológicas adequadas para ser utilizada na extração terciária de petróleo, o custo de produção a partir de glicose torna esta aplicação inviável, devido à alta quantidade de goma necessária ao processo. Por esse motivo, vem aumentando muito o interesse por substratos alternativos como, por exemplo, resíduos industriais que além de serem normalmente descartados, causando sérios problemas ambientais, podem ser utilizados como uma alternativa para produção de polissacarídeos diminuindo os custos de produção $0^{[5]}$.

Levando em consideração os problemas ambientais oriundos do descarte de resíduos, o soro de mandioca resultante do processamento da farinha se destaca pelo alto volume de produção ainda sem um destino comercial, representando, portanto, uma alternativa como substrato para produção de goma xantana. O soro da mandioca é composto de goma residual da extração do polvilho (amido puro), podendo ser usado como fonte de carbono para a produção de biomassa microbiana, além de metabólitos primários ou secundários de processos fermentativos ${ }^{[6]}$.

Autor para correspondência: Líllian V. Brandão, Departamento de Pós-graduação em Engenharia Química, Universidade Federal da Bahia, 
Este trabalho teve como objetivo a obtenção de goma xantana a partir da fermentação do soro de mandioca com diferentes linhagens de Xanthomonas campestris, com ênfase na avaliação do rendimento e determinação da viscosidade aparente.

\section{Experimental}

\section{Microrganismos}

Foram utilizadas quatro linhagens nativas de Xanthomonas campestris: 1182 (Xanthomonas campestris manihotis), 1866 (Xanthomonas campestris campestris), 2103 (Xanthomonas campestris mangiferaeindicae) e 2149 (Xanthomonas campestris pv. campestris) obtidas da Coleção de Culturas do Instituto Biológico em Campinas-SP.

\section{Soro de mandioca}

O soro de mandioca utilizado como substrato fermentativo alternativo foi cedido pela cooperativa de processamento da mandioca em Catu - BA. Essa amostra foi filtrada e armazenada em sacos plásticos de $500 \mathrm{~mL}$ em temperatura de congelamento e utilizada nos processos fermentativos ao longo do desenvolvimento do trabalho.

\section{Análise da composição centesimal do soro de mandioca}

Os teores de umidade, proteína bruta e cinzas do soro de mandioca foram determinados segundo a metodologia da $\mathrm{AOAC}^{[7]}$. O teor de lipídios totais foi determinado pelo método Bligh e Dyer ${ }^{[8]}$. O percentual de carboidratos foi calculado pela diferença entre 100 e a soma das porcentagens de água, proteína, lipídios totais e cinzas. Os valores de carboidratos incluem a fibra total.

\section{Meios de cultura}

Para a preparação do inóculo foi utilizado o meio YM padrão (Yeast-Malt) líquido, contendo (p/v): 1,0\% glicose; 0,5\% peptona bacteriológica; $0,3 \%$ extrato de levedura; $0,3 \%$ extrato de malte ${ }^{[3]}$ para o volume de $50 \mathrm{~mL}$. O pH do meio foi ajustado para 7,0 e a esterilização foi a $121^{\circ} \mathrm{C}$ por 15 minutos em Erlemeyer de $250 \mathrm{~mL}$. $\mathrm{O}$ meio foi esfriado e inoculado com uma alçada da cultura de Xanthomonas campestris e incubado a $28{ }^{\circ} \mathrm{C} / 150 \mathrm{rpm} / 48$ horas.

A repicagem das cepas Xanthomonas campestris foi realizada em placas de Petri e tubos de ensaio. As placas com meio YM-agar (sólido), contendo 1,0\% glicose; $0,5 \%$ peptona bacteriológica; $0,3 \%$ extrato de levedura; $0,3 \%$ extrato de malte e 2,0\% de Agar puro, foram esterilizadas à temperatura de $121^{\circ} \mathrm{C}$ por 15 minutos e esfriadas à temperatura ambiente. Através do plaqueamento foi possível caracterizar visualmente as cepas nativas de Xanthomonas campestris estudadas verificando-se a coloração e aspectos destas.

\section{Produção de goma xantana}

Para a produção de goma xantana foram utilizados dois tipos de meios fermentativos: meio padrão (I) com sacarose como fonte de carbono e meio alternativo (II) com soro de mandioca. Os ensaios de produção de goma xantana foram realizados em triplicata.

O meio fermentativo padrão (I) utilizado foi composto de $2,0 \%$ de sacarose acrescido de $0,01 \%$ de uréia e $0,1 \%$ de $\mathrm{K}_{2} \mathrm{HPO}_{4}$ e $80 \mathrm{~mL}$ de água destilada. $\mathrm{O}$ meio alternativo (II) composto de soro de mandioca integral foi suplementado com uréia e fosfato, nas mesmas concentrações do meio padrão. Os meios fermentativos foram transferidos para erlenmeyers de $250 \mathrm{~mL}$, os $\mathrm{pH}(\mathrm{s})$ foram ajustados para 7,0 e autoclavados a $121^{\circ} \mathrm{C}$ por 15 minutos.
Após o resfriamento à temperatura ambiente, foi adicionado $16 \mathrm{~mL}$ de inóculo de cada cepa nativa $(20 \% \mathrm{v} / \mathrm{v}$ do meio fermentativo). A fermentação aeróbica em batelada foi realizada em incubadora rotatória a $250 \mathrm{rpm}$, na temperatura de $28 \pm 2{ }^{\circ} \mathrm{C}$ por 120 horas.

\section{Recuperação da goma xantana}

Para a separação de goma xantana produzida em cada fermentação, o caldo fermentativo foi centrifugado em uma velocidade de $4400 \mathrm{rpm}$ por 60 minutos à temperatura de $-5{ }^{\circ} \mathrm{C}$, para remoção das células. Ao sobrenadante, depois de separado das células precipitadas, foi adicionado álcool etílico $98{ }^{\circ} \mathrm{GL}$ na proporção de 3 partes de álcool para 1 parte do meio fermentativo. As gomas precipitadas foram retiradas com auxílio de um bastão de vidro e transferidas para placas previamente taradas. As gomas obtidas foram secas em estufa $\left(30 \pm 2{ }^{\circ} \mathrm{C}\right)$ por 72 horas, e em seguida foram moídas.

As células sedimentadas, resultantes da centrifugação, foram secas em estufa $\left(60 \pm 5^{\circ} \mathrm{C}\right)$ por 24 horas, pesadas até peso constante, e o peso seco de massa celular foi calculado.

$\mathrm{O}$ rendimento de goma xantana por litro de meio fermentativo utilizado foi determinado por gravimetria e os valores expressos em g.L $L^{-1}$ (grama por litro de meio fermentativo). Depois de pesada, a goma seca foi retirada das placas por processos de raspagem, triturada em mini-processador e armazenada em embalagens plásticas.

\section{Viscosidade aparente}

As amostras de goma xantana, obtidas pela fermentação da sacarose e do soro de mandioca sintetizadas pelas cepas Xanthomonas campestris que resultaram em melhores rendimentos de produção, foram dissolvidas em água nas composições em \% em peso de $0,5,1,0,1,5$ e 2,0\%. A dissolução ocorreu sob agitação manual constante por aproximadamente 5 minutos em temperatura ambiente, para total absorção da água e formação do gel. As soluções repousaram durante 12 horas à temperatura ambiente antes da leitura da viscosidade visando à retirada de bolhas.

A viscosidade aparente $\left(\mu_{\alpha}\right)$ das gomas obtidas com maiores rendimentos nos dois meios fermentativos (I) e (II), foi determinada em função da taxa de cisalhamento ${ }^{[9]}$, a partir da tensão de cisalhamento e da taxa de cisalhamento medidas em um reômetro Haake Rheotest, com dispositivo de cilindros concêntricos, acoplado a um banho-maria. As medidas foram feitas nas temperaturas de 25, 45,65 e $85^{\circ} \mathrm{C}$ e em taxa de cisalhamento entre 25 e $1000 \mathrm{~s}^{-1}$.

Neste modelo de viscosímetro, utiliza-se $25 \mathrm{~mL}$ de solução de goma xantana. Uma velocidade de rotação variável é aplicada ao cilindro interno e mede-se a tensão de cisalhamento resultante.

Para investigação do comportamento pseudoplástico das soluções de goma, foi realizado o ajuste do modelo de Otswald-de Waele $\left(\sigma=K \cdot \gamma^{n}\right)$ aos dados experimentais, a partir da regressão da lei de potência, usando o software Excel 2003, onde $K$ é o índice de consistência; $n$ é o índice do comportamento do fluxo; $\sigma$ é a tensão de cisalhamento e $\gamma$ é a taxa de cisalhamento. A partir do gráfico $\sigma \times \log \gamma$, obteve-se os valores de $K$ e $n$ e as equações das retas, podendo-se então através da análise estatística, demonstrar o ajuste do modelo aos dados experimentais.

A goma xantana produzida usando a sacarose como fonte de carbono (meio I) na etapa de fermentação foi usada como controle, assim, avaliou-se por comparação, o comportamento das gomas obtidas com a utilização do soro de mandioca (II). Os resultados foram expressos em gráficos da viscosidade aparente em função da taxa de cisalhamento, viscosidade aparente em função da temperatura, viscosidade aparente em função da concentração de 
goma. As unidades de medidas utilizadas foram: centipoise $(\mathrm{cP})$ para a viscosidade aparente, $1 /$ segundo $\left(\mathrm{s}^{-1}\right)$ para a taxa de cisalhamento e miliPascoal $(\mathrm{mPa})$ para a tensão de cisalhamento.

\section{Resultado e Discussão}

A caracterização do soro de mandioca foi efetuada para determinar os constituintes nutricionais presentes no substrato fermentescível que podem ser usados pelas diferentes linhagens de Xanthomonas campestris tanto como fonte de carbono e de nitrogênio, como fonte de micronutrientes necessários para reprodução celular das bactérias e para a produção de goma xantana (Tabela 1). Esse substrato foi usado na forma liquida integral no meio fermentativo alternativo (II) em substituição a água e sacarose do meio controle (I). Ambos os meios fermentativos (I e II) foram suplementados com uréia e $\mathrm{KHPO}_{4}$.

$\mathrm{O}$ soro de mandioca possui alto teor de umidade com apenas $8,69 \%$ de matéria seca. Em relação à base úmida, forma usada como substrato fermentescível, 2,74\% são carboidratos, 3,45\% são proteínas, enquanto que as cinzas representam 1,56\% (Tabela 2). Estes compostos têm grande importância como nutrientes na fermentação pelas bactérias Xanthomonas campestris, uma vez que irão fazer parte dos nutrientes tanto para o crescimento celular como para a biosíntese de goma xantana. Woiciechowski ${ }^{[10]}$ relata que o bagaço da mandioca apresenta um teor de amido que varia entre 50 e $70 \%$. Esse resíduo pode ter diversas aplicações, entre elas, ser usado como substrato na produção de biomassa microbiana.

De acordo com Sutherland ${ }^{[11]}$, uma elevada concentração de nitrogênio é necessária para um rápido crescimento celular, entretanto, quando a concentração de nitrogênio no meio de cultura é muito elevada, a goma xantana produzida possui propriedades reológicas inadequadas. Meios contendo elevado teor de carbono e baixo teor de nitrogênio favorecem ao acúmulo de polímero. A relação C:N para o soro de mandioca é de aproximadamente 0,8:1 (Tabela 1). Segundo Vashitz ${ }^{[11]}$, geralmente os processos industriais procuram utilizar meios que disponibilizem condições tanto para o crescimento como para o acúmulo de goma.

Após a fermentação, as gomas xantanas foram recuperadas e avaliadas visualmente, para verificar as diferenças quanto à coloração depois da precipitação com álcool etílico. A Figura 1 apresenta o aspecto das gomas produzidas pelas linhagens nativas de Xanthomonas campestris com os dois meios fermentativos.

$\mathrm{Na}$ Figura 1, observa-se diferenças quanto ao aspecto e coloração das gomas precipitadas. Foi observado que a goma obtida com sacarose é mais clara com aspecto mais filamentoso, enquanto que a goma obtida com soro de mandioca possui uma coloração mais escura e a presença de grumos.

Tabela 1. Composição centesimal (p/v) do soro de mandioca usado como substrato fermentativo para obtenção de goma xantana.

\begin{tabular}{cc}
\hline Análise & Soro de mandioca $(\%)$ \\
\hline Umidade & $91,31 \pm 0,03$ \\
Cinzas & $1,56 \pm 0,01$ \\
Lipídios totais & $0,94 \pm 0,01$ \\
Proteína bruta & $3,45 \pm 0,03$ \\
Carboidratos & $2,74 \pm 0,02$ \\
\hline
\end{tabular}

Segundo o trabalho de Rottava ${ }^{[13]}$, a diferença morfológica pode ser devida às diferenças no arranjo molecular das cadeias do polímero, sendo necessários estudos mais aprofundados, principalmente quando se deseja correlacionar esta propriedade com a viscosidade das gomas obtidas. Quanto à coloração, as gomas apresentaram pigmentações diferentes oriundas dos meios utilizados na fermentação, mesmo quando as linhagens utilizadas possuíam coloração amarelada.

Os resultados de produção média de goma xantana obtidos pelas diferentes linhagens de Xanthomonas utilizando o meio controle e o meio alternativo, estão relacionados na Tabela 2.

As médias da concentração celular, separada do meio fermentado composto de sacarose e soro de mandioca por centrifugação, foram menores que 1,0 g.L. ${ }^{-1}$.

Constata-se pelos dados da Tabela 2 que a fermentação do soro de mandioca com a linhagens 2103 e 1182 resultaram em 13,83 e 11,72 g.L L $^{-1}$ de goma xantana, respectivamente, após 120 horas de fermentação. Estas produções são aproximadamente três vezes maiores que as obtidas com o meio fermentativo controle (I). Portanto, a partir da fermentação do substrato alternativo foi possível obter uma produção de goma xantana superior à obtida com sacarose, confirmando as constatações de Souza ${ }^{[14]}$, que a produtividade é influenciada não somente pela linhagem do microrganismo, mas também pelo meio de fermentação.

Nas condições testadas a cepa 2149 não converteu os carboidratos presentes no soro de mandioca em goma. Isto se deve provavelmente ao baixo peso molecular da goma produzida, uma vez que se constatou a formação da goma, mas não precipitável com álcool etílico. Suplementando-se o meio fermentativo com outros micronutrientes provavelmente pode ocorrer a biossíntese de goma xantana precipitável a partir desta cepa, uma vez que com a fermentação de outros substratos alternativos contendo soro de leite, casca de coco e casca de maracujá houve a formação de goma xantana precipitável ${ }^{[15,16,17]}$. As cepas 1182 e a 1866 produziram xantana nos dois meios fermentativos testados (padrão e alternativo), e por conseqüência, apresentaram uma maior adaptação à variação da composição dos diferentes substratos.

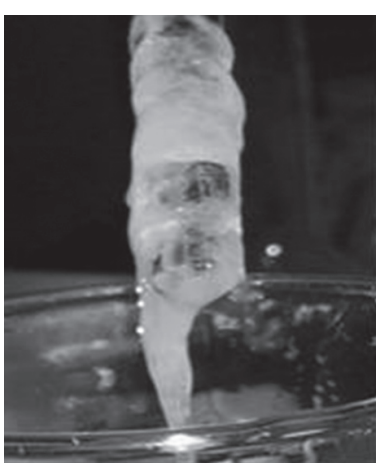

(a)

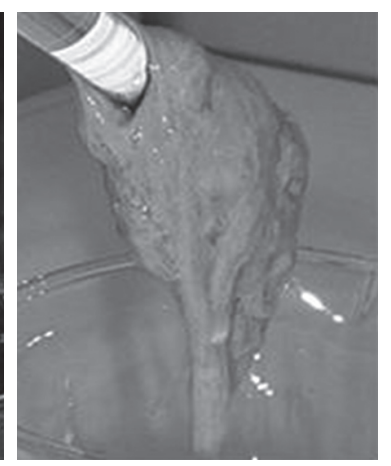

(b)
Figura 1. Aspecto das gomas xantana após precipitação com álcool etílico, e sintetizada pela cepa 2103 a partir de sacarose (a) e a partir de soro de mandioca (b).

Tabela 2. Média da produção (g. $\left.\mathrm{L}^{-1}\right)$ das gomas xantana sintetizadas a partir de sacarose e soro de mandioca pelas cepas de Xanthomonas campestris.

\begin{tabular}{lrrr}
\hline \multicolumn{1}{c}{ Meio fermentativo } & \multicolumn{3}{c}{ Produção de goma xantana por $\boldsymbol{X}$. campestris (g.L ${ }^{-1}$ ) } \\
\cline { 2 - 4 } & \multicolumn{1}{c}{$\mathbf{1 1 8 2}$} & $\mathbf{1 8 6 6}$ & $\mathbf{2 1 0 3}$ \\
\hline (I) Padrão (sacarose) & $3,45 \pm 0,10$ & $3,17 \pm 0,16$ & $4,21 \pm 0,20$ \\
(II) Alternativo (soro de mandioca) & $11,72 \pm 0,07$ & $6,79 \pm 0,10$ & $13,83 \pm 0,08$ \\
\hline
\end{tabular}

${ }^{1}$ n.p.: não precipitou. 
A produção de goma xantana a partir de resíduos (bagaço e soro de mandioca) da mandioca foi realizada por Soccol ${ }^{[16]}$ com rendimento de 14,8 g.L. - $^{-1}$ do biopolímero a $28^{\circ} \mathrm{C}, 160 \mathrm{rpm}$ por 96 horas com a cepa $X$. campestris LPB 01. Segundo Nery ${ }^{[17]}, 6,7,5,6$ e 21,91 g.L. . $^{-1}$ de goma xantana foram obtidas a partir da fermentação de casca de coco verde, casca de maracujá e soro de leite, respectivamente, por X. campestris mangiferaeindicae fermentados a $28{ }^{\circ} \mathrm{C}$, $250 \mathrm{rpm}$ por 120 horas. A partir de melaço de açúcar de beterraba pré-tratado e suplementado com sacarose, obteve-se 53,0 g.L $\mathrm{L}^{-1}$ de goma xantana ${ }^{[18]}$. A fermentação de soro de leite resultou em 13,0-28,0 g.L $\mathrm{L}^{-1}$ de goma xantana ${ }^{[19]}$, enquanto que de resíduos agroindustriais de café, 5,8 g.L $\mathrm{L}^{-1[19]}$; e de resíduo do processamento de suco de maçã, 45 g. $\mathrm{L}^{-1}$ de goma xantana ${ }^{[20]}$. A produção de gelana a partir de resíduo da indústria de $\operatorname{soja}^{[21]}$, a produção de celulose bacteriana a partir do melaço de cana-de-açúcar pré-tratado ${ }^{[22]}$ e a produção de pululana utilizando hidrolisado de torta de $\operatorname{soja}^{[23]}$ são outras bioconversões de resíduos agroindustriais.

As fermentações do soro de mandioca que resultaram em maiores rendimentos de goma xantana $\left(\mathrm{g} . \mathrm{L}^{-1}\right)$ foram as realizadas com as cepas 2103 (Xanthomonas campestris mangiferaeindicae) e 1182 (Xanthomonas campestris manihotis) com produção de 13,83 e 11,72 g.L L $^{-1}$. Estas gomas foram selecionadas para um estudo do perfil de viscosidade aparente em diferentes taxas de cisalhamento, temperaturas e concentrações de goma.
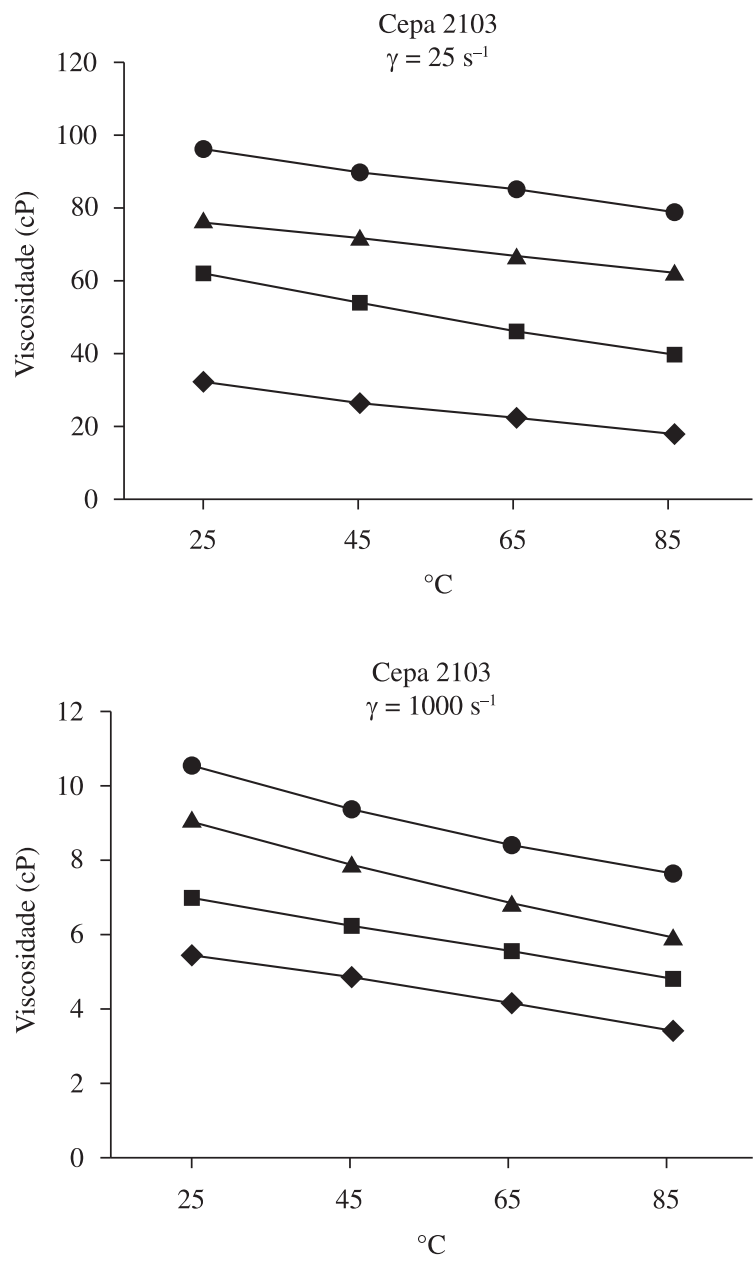

As curvas de viscosidades em função da temperatura para diferentes valores de concentração de xantana e de taxa de cisalhamento são dadas na Figura 2. Pode observar que as viscosidades aparentes das soluções aquosas das gomas xantana obtida à cepa 2103 são mais altas do que aquelas da cepa 1182, em ambas as taxas, mostrando o efeito da linhagem da bactéria sobre a viscosidade e assim, sobre a estrutura molecular do polímero, uma vez que a composição do meio e as condições fermentativas foram exatamente iguais. Na mais baixa taxa de cisalhamento, as soluções aquosas da goma xantana obtida pela fermentação com a cepa 2103 apresentaram valores de viscosidade 2 a 2,5 vezes maiores quando comparadas com as sintetizadas pela cepa 1182, apesar do rendimento de produção serem próximos entre si (Tabela 2). Isto ressalta mais uma vez as características genéticas diferenciadas das linhagens usadas.

Observa-se que a viscosidade aumenta com o aumento da concentração da xantana, contudo maiores taxas de acréscimo são observadas na cepa 2103. Segundo García-Ochoa ${ }^{[3]}$, esse comportamento do aumento da concentração é atribuído às interações intermoleculares, devido à variação das dimensões macromoleculares ${ }^{[24-25-26]}$.

A viscosidade diminui com o aumento da temperatura independentemente da cepa usada na síntese como é esperado. O
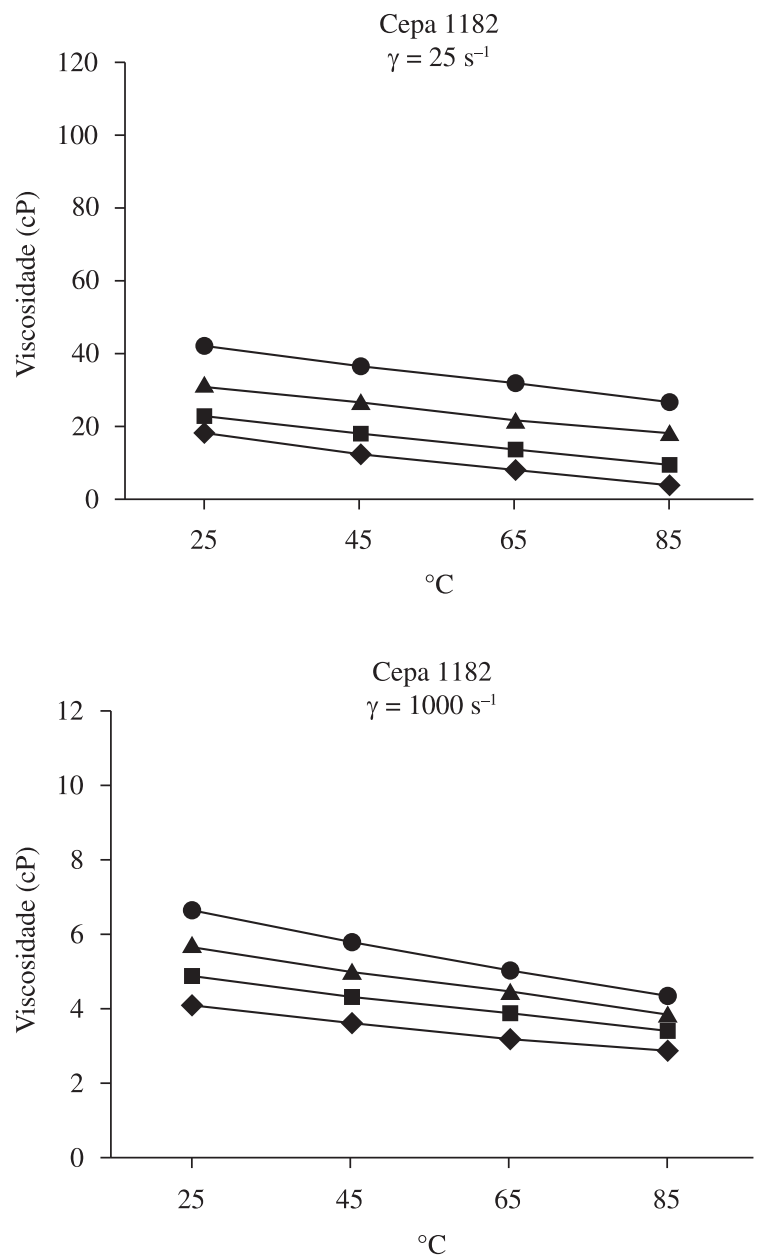

Figura 2. Variação da viscosidade aparente das gomas xantana obtidas a partir do soro de mandioca (cepa 2103; 13,83 g.L $\mathrm{L}^{-1}$ e cepa $1182 ; 11,72$ g.L $\mathrm{L}^{-1}$ ), fixando-se $\gamma \mathrm{em} 25 \mathrm{~s}^{-1}$ e em $1000 \mathrm{~s}^{-1}$, variando-se as concentrações de 0,5 a $2,0 \%$. 
Tabela 3. Valores do índice de fluxo (n) e de consistência (K) das gomas xantana (p/v) produzida a partir do soro de mandioca pelas cepas Xanthomonas campestris mangiferadicae 2103 e Xanthomonas campestris manihotis 1182 nas temperaturas de 25 a $85^{\circ} \mathrm{C}$.

\begin{tabular}{|c|c|c|c|c|c|c|c|c|}
\hline & \multicolumn{8}{|c|}{ Parâmetros reológicos } \\
\hline & \multicolumn{4}{|c|}{ Cepa 2103} & \multicolumn{4}{|c|}{ Cepa 1182} \\
\hline & $0,5 \%$ & $1,0 \%$ & $1,5 \%$ & $2,0 \%$ & $0,5 \%$ & $1,0 \%$ & $1,5 \%$ & $2,0 \%$ \\
\hline $\mathbf{T}\left({ }^{\circ} \mathbf{C}\right)$ & \multicolumn{4}{|c|}{$n$} & \multicolumn{4}{|c|}{$n$} \\
\hline 25 & 0,51 & 0,40 & 0,43 & 0,35 & 0,58 & 0,58 & 0,53 & 0,50 \\
\hline 45 & 0,53 & 0,43 & 0,40 & 0,37 & 0,64 & 0,61 & 0,55 & 0,51 \\
\hline 65 & 0,55 & 0,47 & 0,36 & 0,38 & 0,67 & 0,67 & 0,55 & 0,51 \\
\hline 85 & 0,56 & 0,44 & 0,32 & 0,39 & 0,73 & 0,77 & 0,56 & 0,53 \\
\hline $\mathbf{T}\left({ }^{\circ} \mathbf{C}\right)$ & \multicolumn{4}{|c|}{$K$} & \multicolumn{4}{|c|}{$K$} \\
\hline 25 & 158,78 & 429,93 & 524,08 & 871,10 & 73,21 & 85,96 & 140,05 & 208,40 \\
\hline 45 & 117,94 & 339,20 & 495,57 & 743,67 & 44,73 & 63,27 & 113,27 & 181,89 \\
\hline 65 & 92,95 & 241,44 & 487,34 & 641,51 & 12,55 & 38,34 & 89,95 & 156,98 \\
\hline 85 & 72,80 & 226,38 & 480,93 & 513,82 & 4,46 & 16,13 & 78,23 & 130,67 \\
\hline $\mathbf{T}\left({ }^{\circ} \mathbf{C}\right)$ & \multicolumn{4}{|c|}{$R^{2}$} & \multicolumn{4}{|c|}{$R^{2}$} \\
\hline 25 & 0,988 & 0,984 & 0,995 & 0,989 & 0,990 & 0,994 & 0,989 & 0,987 \\
\hline 45 & 0,992 & 0,988 & 0,996 & 0,990 & 0,985 & 0,997 & 0,994 & 0,988 \\
\hline 65 & 0,995 & 0,995 & 0,984 & 0,989 & 0,983 & 0,996 & 0,994 & 0,992 \\
\hline 85 & 0,995 & 0,996 & 0,986 & 0,997 & 0,997 & 0,997 & 0,994 & 0,992 \\
\hline
\end{tabular}

aumento da temperatura faz com que as cadeias da xantana sofram uma transição de conformação, de uma estrutura ordenada rígida para um emaranhado desordenado, especialmente quando aquecidas acima do ponto de fusão ${ }^{[27]}$. Os grupos acetil e piruvil, presentes na estrutura do biopolímero de xantana, têm uma influência notável nessa conformação estrutural, e segundo Sutherland ${ }^{[28]}$, os grupos acetil estabilizam a forma ordenada, enquanto que o grupo piruvato causa o efeito oposto.

À temperatura ambiente $\left(25^{\circ} \mathrm{C}\right)$ e a $25 \mathrm{~s}^{-1}$, a viscosidade aparente das soluções a $2 \%$ das gomas xantana obtidas a partir do soro de mandioca pelas cepas 2103 e 1182 são de 96,14 e 41,78 cP, respectivamente. Estes valores são aproximadamente 3 e 2 vezes maiores do que as viscosidades para a concentração de $0,5 \%$ (32,49 e 18,09 cP, respectivamente), Figura 2.

Em taxas de cisalhamento de $1000 \mathrm{~s}^{-1}$ e $25^{\circ} \mathrm{C}$, a viscosidade aparente das soluções a $2 \%$ das gomas xantana obtidas com as cepas 2103 e 1182 são de 9,85 e 6,63 cP, respectivamente. Estes valores são aproximadamente 1,9 e 1,5 vezes maiores do que as viscosidades para a concentração de $0,5 \%$ (5,27 e 4,09 cP, respectivamente). A concentração da xantana exerce um efeito menos pronunciado sobre a viscosidade aparente das soluções nessa taxa do que a $25 \mathrm{~s}^{-1}$. O mesmo comportamento, de ambas as taxas, se observa nas outras temperaturas.

O ajuste do modelo de Ostwald-de-Waele aos dados experimentais apresentaram coeficientes de correlação $\left(\mathrm{R}^{2}\right)$ que variaram entre 0,983 e 0,997 , indicando que o modelo pode ser usado na representação do comportamento das soluções de todas as gomas produzidas pelas duas cepas, (Tabela 3 ).

O valor de $n$, em todos os casos, foi menor do que uma unidade $(n<1)$, o que comprova o comportamento pseudoplástico das soluções, (Tabela 3). Em geral, $n$ aumenta com o aumento da temperatura. À temperatura de $45{ }^{\circ} \mathrm{C}$ por exemplo, observa-se que para a goma obtida com a cepa $2103, n$ varia entre 0,37 a 0,53 quando a concentração varia entre 2 e $0,5 \%$. Para a cepa $1182, n$ varia entre 0,51 a 0,64 nos mesmos limites de concentração, assim as soluções obtidas com a cepa 2103 desviam-se mais do comportamento Newtoniano do que aquelas obtidas com a cepa 1182, evidenciando mais uma vez que as estruturas moleculares das xantanas obtidas com estas cepas são diferentes entre si. O mesmo comportamento é observado nas temperaturas de 25,65 e $85^{\circ} \mathrm{C}$.
Marcotte et al., ${ }^{[29]}$ obtiveram valores de $n$ entre 0,21 e 0,18 para concentrações das soluções aquosas de goma xantana entre 1 e $3 \%$ a $20{ }^{\circ} \mathrm{C}$. Segundo Speers ${ }^{[30]}$, a magnitude de $n$ e a dependência dos valores com a concentração em solução aquosa são dependentes do tamanho das moléculas.

$O$ índice de consistência aumenta com o aumento da concentração e foi maior para a solução de xantana obtida com a cepa 2103 confirmando o comportamento já observado a partir das medidas de viscosidade.

Apesar dos biopolímeros sintetizados pelas cepas nativas 1182 (Xanthomonas campestris manihotis) e 2103 (Xanthomonas campestris mangiferaeindicae) com soro de mandioca apresentaram viscosidades aparentes diferentes quando comparadas entre si, elas podem encontrar aplicações em produtos que exigem menor poder espessante, por exemplo, na área alimentícia e farmacêutica. Novos ensaios para otimização do processo podem ser realizados com o objetivo de melhorar a qualidade da goma.

\section{Conclusão}

É possível produzir goma xantana a partir da fermentação do soro de mandioca com as cepas nativas de $X$. campestris manihotis 1182, X. campestris campestris 1866 e X. campestris mangiferaeindicae 2103 a $28{ }^{\circ} \mathrm{C}, 250 \mathrm{rpm}$ por 120 horas, com diferentes rendimentos. A goma xantana não foi produzida pela linhagem de X. campestris pv. Campestris 2149, necessitando de estudos adicionais quanto à suplementação de micronutrientes do meio e condições fermentativas.

Considerando o baixo custo do soro de mandioca, a sua bioconversão a um produto de alto valor agregado como a goma xantana pode representar uma alternativa para a utilização deste resíduo. A linhagem de Xanthomonas causa grandes variações no rendimento e na viscosidade da goma xantana sintetizada. $\mathrm{O}$ maior rendimento $\left(13,83\right.$ g. $\left.\mathrm{L}^{-1}\right)$ foi obtido pela bioconversão do soro de mandioca pela cepa 2103 que também gerou soluções de xantana de valores de viscosidade mais altos $(96,14 \mathrm{cP}$ para solução 2,0\%, $\gamma=25 \mathrm{~s}^{-1}$ a $25^{\circ} \mathrm{C}$ ) do que as soluções obtidas com as outras cepas. Este comportamento é surpreendente, pois em geral, tem-se observado que quanto maior o rendimento da síntese menor é a viscosidade. Todas as soluções apresentaram comportamento pseudoplástico característico das soluções de goma xantana. 


\section{Agradecimentos}

O presente trabalho foi realizado com o apoio do Conselho Nacional de Desenvolvimento Científico e Tecnológico - CNPQ Brasil.

\section{Referências Bibliográficas}

1. Bradbury, J. F. - Williams \& Wilkins, 1, p.199-210 (1984).

2. Vendruscolo, C. T. - "Produção e caracterização do biopolímero produzido por Beijerinckia sp isolada do solo cultivado com cana de açúcar da região de Ribeirão Preto-São Paulo-Brasil”, Tese de Doutorado, Universidade de Campinas, Brasil (1995).

3. García-Ochoa, F.; Santos, V. E.; Casas, J. A. \& Gómez, E. Biotechnol. Adv., 18, p.549-579 (2000).

4. Moreira, A. S. - "Produção, caracterização e aplicação de biopolímero sintetizado por cepas de Xanthomonas campestris pv pruni", Tese de Doutorado, Universidade Federal de Pelotas, Brasil (2002).

5. Yoo, S. D. \& Harcum, S. W. - Bioresour. Technol., 70, p.13-15 (1999).

6. Chisté, R. C. - "Estudo das propriedades físico-químicas e microbiológicas na produção de farinha de mandioca dos grupos seca e d'água, subgrupo fina, tipo 1", Trabalho de Graduação, Centro de Ciências Naturais e Tecnologia, Brasil (2006).

7. Association of Official Analytical Chemists. - "Official methods of analysis”, Rev Arlington (ed.), AOAC, Maryland (1995).

8. Bligh, E. G. \& Dyer, W. J. - Can. J. Biochem, 37, p.911 (1959).

9. Chhabra, R. P. \& Richardson, J. F. - "Non-newtonian flow in the process industries fundamentals and engineering applications", Butterworth Heinemann, Great Britain (1999).

10. Woicienchowsky, A. L. - "Desenvolvimento de bioprocesso para a produção de goma xantana a partir de resíduos agroindustriais e de mandioca", Tese de Doutorado, Universidade Federal do Paraná, Brasil (2001).

11. Sutherland, I. W. - Advanc. in Microbial Physiol, 23, p.80-142 (1982).

12. Vashitz, O \& Sheintuch, M. - Biotechnol. and Bioengineer, 37, p.383-385 (1991).

13. Rottava, I. - "Seleção de linhagens de Xanthomonas sp para produção de goma xantana”, Dissertação de Mestrado, Universidade Regional Integrada do Alto do Uruguai e das Missões, Brasil (2005).
14. Souza, A. da S. \& Vendruscolo, C. T. - Ciência e Engenharia, 8, p.115-123 (2000).

15. El-Salam, M. H. A.; Fadel, M. A. \& Murad, H. A. - Journ. of Biotechnol, 33, p.103-106 (1994).

16. Soccol, C. R.; Woicienchowsky, A. L. \& Pandey, A. - PI 0007342-3 A: Produção de goma xantanapor fermentação a partir de mandioca, batata e resíduos das agroindustrias cafeeira. de batata e de mandioca (2002).

17. Nery, T. B. R. - "Produção e caracterização de goma xantana obtida com novas culturas liofiolizadas de Xanthomonas campestris pv. utilizando resíduos industriais”, Dissertação de Mestrado, Universidade Federal da Bahia, Brasil (2007).

18. Kalogiannis, S.; Iakovidou, G.; Liakopoulou-Kyriakides, M.; Kyriakides, D. A. \& Skaracis, G. N. - Process Biochemistry, 39, p.249-256 (2003).

19. Nitschke, M.; Rodrigues, V. \& Schinatto, L. F. - Ciência e Tecnol. de Alimen, 21, p.82-85 (2001).

20. Druzian, J. I. \& Pagliarini, A. P. - Ciência e Tecnol. de Alimen, 27, p.787-792 (2007).

21. Jin, H.; Lee, N. K.; Shin, M. K.; Kim, S. K..; Kaplan, D. L. \& Lee, J. W. - Biochem. Engineer. Journ, 16, p.357-360 (2003).

22. Bae, S. \& Shoda, M. - Biotechnol. Progress, 20, p.1366-1371 (2004).

23. Boza, Y.; Neto, L. P.; Costa, F. A. A. \& Scamparini, A. R. P. - Process Biochemist, 39, p.1201-1209 (2004).

24. Sutherland, I. - Microbiol. Today, 29, p.70-71 (2002).

25. Fox, R. W. \& McDonald, A. T. - "Introdução à Mecânica dos Fluidos", Guanabara Dois, Rio de Janeiro (1981).

26. Urlacher, B. \& Noble, O. Blackie Academic \& Professional, p.284-312, (1997).

27. Medeiros, A. S.; Moreira, A. S.; Vendruscolo, C. T.; Conceição, J. J. \& Vendruscolo, J. L. - Ciência e Tecnol. de Aliment., 3, p.9-29 (2000).

28. Sutherland, I. W. Biotechnology, 6, p.613-657 (1996).

29. Marcotte, M.; Taherian, A. R. \& Ramaswamy, H. S. - Food Resear. Inter., 34, p.695-703 (2001).

30. Speers, R. A. \&Tung, M. A. - Journ. of Food Scien., 51, p.96-98 (1986).

Enviado: $29 / 09 / 09$

Reenviado: 09/02/10

Aceito: $19 / 02 / 10$

DOI: $10.1590 / \mathrm{S} 0104-14282010005000029$ 